\title{
Time taken to perform a rapid sequence intubation within a simulated prehospital environment
}

\author{
C Vincent-Lambert, ND AET, NHD PSE, NHD FST, BTech EMC, MTech Ed, PhD HPE; OrcID: 0000-0002-7312-6654; R Loftus, BHS EMC \\ Department of Emergency Medical Care, Faculty of Health Sciences, University of Johannesburg, South Africa
}

Corresponding author: C Lambert (clambert@uj.ac.za)

\begin{abstract}
Background. Rapid sequence intubation (RSI) involves inducing unconsciousness and paralysis in rapid succession in order to facilitate endotracheal tube placement. RSI has recently been introduced to the scope of practice of South African prehospital emergency care practitioners (ECPs). Despite this, there remains limited evidence supporting the efficacy and safety of RSI within this context. While in-hospital studies have shown that it can take 20 minutes or more to perform an RSI, little is known about the time taken to perform the procedure in the prehospital setting.

Objective. To measure the time taken to perform an RSI in a simulated prehospital environment.

Methods. A sample of final-year ECP students were video-recorded performing RSIs on a mannequin within a simulated prehospital environment. Data were gathered through an analysis of the recordings, allowing for the capturing of times taken to complete each of the phases of a RSI.

Results. A mean time of 15 minutes 5 seconds was recorded to complete the procedure. This was shorter than times reported for in-hospital studies. Conclusion. RSI is a potentially harmful procedure if improperly performed and has the potential to create delays in transport that may not always be in the patient's best interest. With a mean time of 15 minutes 5 seconds, the performance of RSI by ECP students in the simulated prehospital environment was faster than expected. Further research is recommended to explore the relationship between the performances observed in this mannequin-based study with those in authentic prehospital settings.
\end{abstract}

Keywords. Airway management, prehospital, intubation, anaesthesia.

South Afr J Crit Care 2019;35(2):70-73. https://doi.org/10.7196/SAJCC.2019.v35i2.368

\section{Contribution of study}

- This study adds to a currently limited body of knowledge surrounding the performance of out-of-hospital anaesthesia by emergency care practitioners in the African context.

- The study highlights the fact that while prehospital rapid sequence intubation may be a lifesaving procedure, anaesthetising patients in an uncontrolled prehospital environment is not without risk. An important consideration that needs to be taken into account when making a decision on whether or not to perform the procedure within the prehospital setting is the potential delay this might have on transport time and arrival at the receiving facility.

A small percentage of critically ill or injured patients require urgent airway interventions. ${ }^{[1]}$ These range from simple mouth-opening, headtilting, chin-lifting and/or jaw-thrusting manoeuvres to more advanced procedures such as endotracheal intubation (ETI). ${ }^{[2]}$ Patients who require ETI in the emergency setting commonly undergo a procedure called rapid sequence intubation (RSI). As the name implies, RSI is a sequential process of using pharmacological agents to rapidly induce unconsciousness followed by paralysis, in order to facilitate laryngoscopy and ETI. ${ }^{[2]}$ RSI, is considered to be a fast and safe way of securing a definitive airway, with reported improved first-pass success rates. $^{[3-5]}$ That said, it is acknowledged to be an invasive and potentially harmful procedure if improperly performed. For this reason, in many parts of the world RSI remains a predominantly in-hospital anaesthetic procedure, which is most commonly only performed by anaesthetists and emergency department physicians. ${ }^{[6]}$ In South Africa (SA), RSI has recently been introduced to the scope of practice of prehospital emergency care practitioners (ECPs). Its introduction has, however, not been without controversy, as there remains limited evidence either supporting or refuting the efficacy and safety of RSI within the local prehospital context. ECPs are prehospital acute care providers who register as independent practitioners post completion of a full-time 4 -year professional bachelor's degree in emergency medical care at various universities around the country. SA ECP students are taught how to perform ETI in their second year of study. ${ }^{[7,8]}$ The initial teaching is theoretical and mannequin-based, with practicals being done within the simulation laboratory environment, where students are able to learn the core concepts and master the psychomotor skills associated with the procedure. ${ }^{[9]}$ Learning via simulation is then coupled with clinical teaching and learning experiences in years 2 - 4 at emergency departments (EDs) and operating rooms of academic teaching hospitals. This is followed by clinical learning shifts with qualified ECPs in the authentic prehospital environment. ${ }^{[10]}$

Aside from potentially harmful side-effects associated with the pharmacological agents used and the procedure itself, the performance of prehospital RSI also has the potential to increase on-scene time. Such delays in transport may not always be in the patient's best interest. ${ }^{[11,12]}$ 
In-hospital studies have shown that an RSI can take 20 minutes or more to complete. ${ }^{[4]}$ Consequently, prehospital caregivers need to critically weigh up the time taken to perform interventions such as RSI against the need for such an intervention, and the potential delays these may have on transportation and arrival at the receiving facility.

Apart from extended on-scene time, it could also be argued that in-hospital RSI is both easier and safer than prehospital RSI owing to the fact that the required equipment is laid out in a controlled environment that is more favourable for fast and efficient completion of the procedure. In-hospital staff also have access to trained team members to assist and support them as required. The SA prehospital environment is quite different, as the 2017 EMS regulations of the National Health Act (No. 61 of 2003$)^{[13]}$ inexplicably still allow for primary response vehicles to be manned by a single crew member. In addition, the required airway management equipment is not pre-prepared and laid out as it is in an ED; rather, it is stored inside closed pouches within emergency medical bags in the boot of the response vehicle. It is conceivable that such factors, together with the often uncontrolled and chaotic prehospital emergency care setting, could impact on the time taken by ECPs to perform RSI in their operating context. That said, we could not find any published literature that described the time taken by ECPs or ECP students to complete an RSI within a prehospital context. This being the case, we felt that a useful starting point would be to attempt to measure the time taken by a sample of final-year ECP students to perform a RSI within a simulated prehospital environment.

\section{Methods}

The study was conducted in the simulation laboratories at the University of Johannesburg (UJ), SA. The participants were 10 ECP students in their fourth and final year of study. All had previously been found to be competent in performing RSI. ${ }^{[10,14,15]}$ Given the exploratory descriptive nature of the study, a sample size of 10 participants was decided upon as this accounted for $50 \%$ of the fourth-year class. The selection of the 10 members of the class to participate was randomised using a cellularbased application called arc4rand version 2.1.2 (Apikrit Panichevaluk, Thailand) found on the Apple iPhone application store (Apple Inc., USA). Ethical approval for the study was granted by the University of Johannesburg Faculty of Health Sciences Research Ethics Committee (ref. no. REC-01-103-2017).

Data collection spanned a 2-day period. All participants performed the RSI on the same adult advanced life support (ALS) training mannequin. The equipment supplied was: one standard suction unit; one standard-size portable oxygen cylinder; one ALS drug bag; and one ALS medical bag with the relevant airway equipment in pouches. The airway kit comprised: one standard bulb light laryngoscope; Macintosh blades of various sizes; endotracheal tubes of various sizes; an oesophageal detection device; tracheostomy tape; a linen-saver; one adult stylet; one adult bougie; one $10 \mathrm{~mL}$ syringe; and one adult end-tidal carbon dioxide detector. Bailout devices that were provided consisted of laryngeal mask airways of various sizes, one King-LT airway and one surgical cricothyroidotomy kit.

The mannequin was arranged in a supine position on the floor with a pre-attached electrocardiogram monitor and a pre-sited Ringer's Lactate intravenous solution with a (20 drops per second) administration set with no fluid treatment initiated. Each participant had the opportunity to check the equipment prior to the beginning of the simulated procedure.

The filming of the procedure was completed with a Sony Handy Cam camera (HDR-XR160). The times were captured by the video camera.
A fourth-year student with the same level of experience and training acted as an assistant for each participant. The assistant was restricted to providing assistance commensurate with an intermediate life support scope of practice.

Data analysis was descriptive in nature. The audiovisual recordings were analysed to capture the associated time intervals for each phase of the procedure in minutes and seconds. These raw data were entered into an Excel (Microsoft, USA) spreadsheet. Simple statistical formulae were applied to calculate the median, mean and interquartile range (IQR) for each of the relevant data sets. This was done for each of the seven phases associated with performance of the procedure, including a calculation of the mean overall time taken to perform the RSI. The seven phases we considered were as follows, although it should be noted that certain of the phases may have overlapped with one another.

- Preparation phase: This phase began at the start of the airway assessment and checks, and ended once the airway had been assessed and all of the airway management equipment had been prepared and checked.

- Pre-oxygenation phase: This phase began with the start of efforts to pre-oxygenate, and ended once laryngoscopy was attempted (with the tip of the blade entering the mannequin's mouth).

- Pre-treatment phase: This phase began once preloading of fluid started, and ended once the selected pre-loaded fluid bolus was delivered.

- Paralysis and induction phase: This phase began once the participants began to draw up their induction and paralytic agents, and ended after both were administered.

- Positioning phase: This phase started once the induction and paralytic agents were administered, and ended when the participant had positioned him/herself and the patient in a position to intubate.

- Placement and proof of placement: This phase started once the laryngoscope was picked up, and ended once the tube had been placed and the laryngoscope was removed from the mouth.

- Post-intubation sedation management: This phase began at the start of the confirmation checks of the tube placement, and ended once the tube had been secured and the post-RSI sedation and paralysis agents had been administered.

\section{Results}

The fastest time, slowest time, median, mean and IQR are provided in Table 1 for each of the seven phases described above.

\section{Discussion \\ Preparation phase}

Bernhard et al. ${ }^{[16]}$ emphasise that every effort should be made to prepare correctly, as this supports a first-pass success ETI. Kovacs and Law $^{[2]}$ advocate the mnemonic STOP-IC-BARS as a way of guiding preparation for the procedure $(\mathrm{STOP}=$ Suction Tubes, Oxygenation and positive pressure, and Pharmacology; IC = Intravenous access, Connect to monitors and confirmation devices; BARS = Blades and bougie, Alternative intubation devices, Rescue oxygenation technique and Surgical airway equipment). In the present study, we noted that the majority of participants used similar mnemonics or mental checklists. We recorded a mean time to complete this preparation phase of 5 minutes 55 seconds, but we could not find any literature dealing with this time interval for RSI, and so no comparisons could be drawn.

\section{Pre-oxygenation phase}

It is advocated that prior to an RSI, pre-oxygenation is a mandatory practice, for a minimum of 3 minutes. ${ }^{[17]}$ The mean for our participants 
Table 1. Time taken to compete phases associated with rapid sequence intubation*

\begin{tabular}{|c|c|c|c|c|c|}
\hline Phase & Fastest time & Slowest time & Median & Mean & IQR \\
\hline Preparation & $2 \mathrm{~m} 48 \mathrm{~s}$ & $9 \mathrm{~m} 46 \mathrm{~s}$ & $5 \mathrm{~m} 55 \mathrm{~s}$ & $5 \mathrm{~m} 55 \mathrm{~s}$ & $3 \mathrm{~m} 58 \mathrm{~s}$ \\
\hline Pre-oxygenation & $7 \mathrm{~m} 03 \mathrm{~s}$ & $11 \mathrm{~m} 02 \mathrm{~s}$ & $9 \mathrm{~m} 42 \mathrm{~s}$ & $10 \mathrm{~m} 47 \mathrm{~s}$ & $2 \mathrm{~m} 51 \mathrm{~s}$ \\
\hline Pre-treatment & $4 \mathrm{~m} 10 \mathrm{~s}$ & $10 \mathrm{~m} 38 \mathrm{~s}$ & $8 \mathrm{~m} 41 \mathrm{~s}$ & $9 \mathrm{~m} 25 \mathrm{~s}$ & $4 \mathrm{~m} 09 \mathrm{~s}$ \\
\hline Paralysis and induction & $2 \mathrm{~m} 03 \mathrm{~s}$ & $7 \mathrm{~m} 32 \mathrm{~s}$ & $5 \mathrm{~m} 49 \mathrm{~s}$ & $6 \mathrm{~m} 36 \mathrm{~s}$ & $3 \mathrm{~m} 15 \mathrm{~s}$ \\
\hline Positioning & $0 \mathrm{~m} 04 \mathrm{~s}$ & $0 \mathrm{~m} 57 \mathrm{~s}$ & $0 \mathrm{~m} 40 \mathrm{~s}$ & $0 \mathrm{~m} 37 \mathrm{~s}$ & $0 \mathrm{~m} 28 \mathrm{~s}$ \\
\hline Placement and proof of placement & $0 \mathrm{~m} 11 \mathrm{~s}$ & $0 \mathrm{~m} 53 \mathrm{~s}$ & $0 \mathrm{~m} 30 \mathrm{~s}$ & $0 \mathrm{~m} 29 \mathrm{~s}$ & $0 \mathrm{~m} 17 \mathrm{~s}$ \\
\hline Post-intubation sedation management & $1 \mathrm{~m} 48 \mathrm{~s}$ & $3 \mathrm{~m} 00 \mathrm{~s}$ & $2 \mathrm{~m} 16 \mathrm{~s}$ & $2 \mathrm{~m} 23 \mathrm{~s}$ & $0 \mathrm{~m} 52 \mathrm{~s}$ \\
\hline Overall time to complete the procedure & $10 \mathrm{~m} 00 \mathrm{~s}$ & $15 \mathrm{~m} 17 \mathrm{~s}$ & $14 \mathrm{~m} 02 \mathrm{~s}$ & $15 \mathrm{~m} 05 \mathrm{~s}$ & $2 \mathrm{~m} 00 \mathrm{~s}$ \\
\hline
\end{tabular}

to accomplish this was 10 minutes 47 seconds, which was more than three times as long as the minimum.

\section{Pre-treatment phase}

Hypotension and hypoxia have potential adverse events associated with RSI. ${ }^{[2]}$ Fluid boluses of $10-20 \mathrm{~mL} / \mathrm{kg}$ together with pre-oxygenation are advised prior to the administration of induction agents. ${ }^{[17]}$ Our participants were noted to opt for a preloaded fluid bolus of $10 \mathrm{~mL} / \mathrm{kg}$ prior to administration of the RSI agents; this amounted to around $1000 \mathrm{~mL}$. The rate at which the fluid was run varied depending on the rate at which fluid was run through the administration set. We could not find literature dealing with the time taken for this phase of RSI.

\section{Paralysis and induction phase}

In this phase, induction and paralysis agents are prepared and administered rapidly, one after the other, with the goal of inducing unconsciousness followed by muscle relaxation in this order. ${ }^{[2]}$ This is done to control physiological responses that are undesirable during laryngoscopy, as well as facilitation of the ETI that will ensue. This critical phase took a mean time of 6 minutes 36 seconds to complete.

\section{Positioning phase}

It is recommended that the practitioner assumes an optimal position to achieve the best possible view of the glottis inlet, and ensure firstpass successes. The clinician's positioning in relation to the patient is important, as is the positioning of the patient's head in relation to the end of the stretcher; the sniffing position is advised to achieve the best view. ${ }^{[2]}$ The administration of paralytic agents makes it important for the practitioner to rapidly place themselves in the best possible position to facilitate the ETI. The fastest time captured for this phase was just 4 seconds. That said, the time taken to get into a position to intubate may differ in prehospital settings, such as cases of motor vehicle accidents where patients may be confined or entrapped.

\section{Placement phase}

Endotracheal tube placement may be performed once the patient is induced and the paralytic has taken effect. This phase should essentially be a short period to prevent hypoxia due to a state of induced apnoea. Pre-oxygenation and close monitoring of oxygen saturation are thus crucial steps to limit the opportunity for hypoxia to occur during this phase. Kovacs and Law ${ }^{[2]}$ describe this period as taking no longer than 30 - 45 seconds in most cases.

Our participants recorded a mean time of 30 seconds for endotracheal tube placement, falling within Kovacs and Law's recommended period.

\section{Post-intubation and sedation phase}

This phase begins once the endotracheal tube is placed. Objective assessments are done to ensure correct placement. These include using an oesophageal detection device, as well as the use of end-tidal carbon dioxide monitoring. ${ }^{[2]}$ The phase ended with the administration of postinduction sedation agents.

With a mean time of 2 minutes 22 seconds, the phase was completed well before the effects of the paralytic agent would have worn off.

\section{Total time to completion}

The total time to completion was captured from the initiation of the first phase and ending at the completion of the last phase. It is important to recognise that many of the initial steps occurred concurrently. With this in mind, the shortest time was captured at only 10 minutes. The mean time of 15 minutes 5 seconds taken by our participant sample compares favorably with the 20 minutes noted for previous in-hospital studies. ${ }^{[4]}$

\section{Conclusion}

RSI is an advanced airway management procedure that facilitates ETI in adults and children. The procedure includes pre-oxygenation, and rapid pharmacological induction of unconsciousness followed by neuromuscular blockade to enable placement of an endotracheal tube. ${ }^{[18]}$ RSI in a prehospital setting remains a contentious issue, as the procedure itself is invasive and not without risk.

All prehospital interventions, including RSI, have the potential to increase on-scene times. Such delays in transport may not always be in the patient's best interests. Consequently, prehospital caregivers need to critically weigh up the time that they will take to perform procedures such as RSI within the prehospital environment against the risks, benefits and acute need for such interventions. Given the times reported for similar in-hospital studies, and the fact that our participants were students with limited clinical experience operating in a simulated prehospital setting, the mean time of 15 minutes 5 seconds recorded for the performance of the procedure in the present study was faster than we predicted. That said, we could not find any literature regarding what would be considered an acceptable time frame for the completion of an RSI within a prehospital environment. While the term itself implies 'rapid' performance of the procedure, patients in a prehospital context are unique in the environment in which they are found and treated. This limits one's ability to make a universal judgement relating to what is considered 'fast' or 'slow' for the performance of prehospital RSI. Further research is recommended to explore the relationship between the performances observed in this mannequin-based study in the simulated environment with those of qualified emergency care practitioners practising in an authentic prehospital acute care setting. 
Author contributions. CVL supervised the research and wrote this article; RL gathered the raw data and wrote the report upon which the article is based. Acknowledgements. We wish to thank the participants for giving up their valuable time to participate in the study.

Funding. None.

Conflicts of interest. None.

1. Lossius HM, Røislien J, Lockey DJ. Patient safety in prehospital emergency tracheal intubation: A comprehensive meta-analysis of the intubation success rates of EMS providers. Crit Care 2012;16(1)1-9. https://doi.org/10.1186/cc11189

2. Kovacs G, Law J. Airway Management in Emergencies. New York: McGraw-Hill, 2008:33-179

3. Hubble M, Brown L, Wilfong D, Hertelendy A, Benne R, Richards M. A meta-analysis of prehospital airway control techniques part 1: Orotracheal and nasotracheal intubation success rates. Prehospital Emerg Care 2010;14(3):377-401. https://doi.org/10.3109/10903121003790173

4. Butler JM, Clancy M, Robinson N, Driscoll P. An observational survey of emergency department rapid sequence intubation. Emerg Med J 2001;18(5):343-348. https://doi.org/10.1136/emj.18.5.343

5. Kerry B, Rinderknecht A, Geis G, Nigrovic L, Mittigia M. Rapid sequence intubation for paediatric emergency patients: Higher frequency of failed attempts and adverse effects found by video review. Ann Emerg Med 2012;60(3):251-259. https://doi.org/10.1016/j.annemergmed.2012.02.013

6. Boyle A, Atkinson P, Ahmed V, Kark W. Emergency physician-performed rapid sequence induction and system changes reduce time to intubation in critically ill emergency medicine patients. Eur J Med 2008;15(4):243-244. https://doi.org/10.1097/MEJ.0b013e3282f12f64

7. Van Tonder B. Learner Guide for Emergency Medical Care Theory II. University of Johannesburg, 2017. http://www.uj.ac.za/EN/Faculties/health/departments/emc/Pages/default.aspx (accessed 4 February 2017).

8. Van Tonder B. Learner Guide for Clinical Practice II. University of Johannesburg, 2017:1-18. http:// www.uj.ac.za/EN/Faculties/health/departments/emc/Pages/defaultaspx (accessed 4 February 2017).
9. Van Tonder B. Learning Guide for EMC Practical II. University of Johannesburg,2017:1-18. http:// www.uj.ac.za/EN/Faculties/health/departments/emc/Pages/default.aspx, (accessed 4 February 2017).

10. Van Nugteren B. Learning Guide for Clinical Practice III. University of Johannesburg, 2017:1 18. http://www.uj.ac.za/EN/Faculties/health/departments/emc/Pages/default.aspx (accessed 5 February 2017).

11. Kulla M, Helm M, Lefering R, Walcher F. Prehospital endotracheal intubation and chest tubing does not prolong the overall resuscitation time of severely injured patients: A retrospective, multicentre study of the trauma registry of the German Society of Trauma Surgery. Emerg Med 2012;29(6):497-501. https://doi.org/10.1136/emj.2010.107391

12. Brown J, Rosenqart M, Forsythe R, et al. Not all prehospital time is equal: Influence of scene time on mortality. J Acute Trauma Surg 2016;81(1):93-100. https://doi.org/10.1097/ TA. 0000000000000999

13. South Africa. National Health Act No. 61 of 2003. Emergency medical services regulations. Government Gazette No. 41287, 1 December 2017 (published under Government Notice 1320).

14. Van Nugteren B. Learning Guide For EMC III Theory. University of Johannesburg, 2017:143. http://www.uj.ac.za/EN/Faculties/health/departments/emc/Pages/default.aspx. (accessed 5 February 2017).

15. Van Nugteren B. Learning Guide For EMC III Practical. University of Johannesburg, 2017:15 http://www.uj.ac.za/EN/Faculties/health/departments/emc/Pages/default.aspx. (accessed 5 February 2017).

16. Bernhard M, Becker TK, Gries A, Knapp J, Wenzel V. The first shot is often the best shot: Firstpass intubation success in emergency airway management. Anesth Analg 2015;121(5):1389-1393. https://doi.org/10.1213/ANE.0000000000000891

17. Van Nugteren B. RSI OSCE. University of Johannesburg, 2016:1-23. http://www.uj.ac.za/EN/ Faculties/health/departments/emc/Pages/defaultaspx (accessed 5 February 2017).

18. Stein M, Botha M, Kramer E, et al. Position statement: Prehospital rapid sequence intubation. S Afr Med J 2011;101(3):163.

Accepted 19 August 2019 